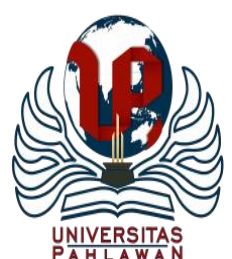

Jurnal Abdidas Volume 2 Nomor 1 Tahun 2021 Halaman 114-120

JURNAL ABDIDAS

http://abdidas.org/index.php/abdidas

\title{
Pelatihan Batik Berbasis Kreativitas pada Siswa Sekolah Dasar Kota Padang Panjang
}

\author{
Yulimarni $^{1}$, Ahmad Bahrudin ${ }^{2}$, Widdiyanti $^{3}$, Wisnu Prastawa ${ }^{4}$, Taufik Akbar ${ }^{5 凶}$
}

Prodi Kriya Seni, Institut Seni Indonesia Padang Panjang, Indonesia ${ }^{1,2,3,4,5}$

E-mail: yulimarni@isi-padangpanjang.ac.id ${ }^{1}$, ahmadbahrudin@isi-padangpanjang.ac.id ${ }^{2}$, widdiyanti@isi-padangpanjang.ac.id ${ }^{3}$, lempungart@yahoo.com ${ }^{4}$, taufik723@gmail.com ${ }^{5}$

\begin{abstract}
Abstrak
Batik adalah karya seni asli Indonesia yang harus terus dilestarikan. Salah satu caranya adalah dengan mengenalkannya pada anak-anak. Kegiatan pengabdian masyarakat ini adalah berupa pelatihan batik yang bertujuan mengenalkan batik dan berlatih membatik sebagai langkah pelestarian dan mengasah kreativitas siswa SD di Kota Padang Panjang. Metode yang digunakan dalam kegiatan adalah ceramah, demonstrasi dan pelatihan. Hasil kegiatan menunjukkan antusias siswa yang tinggi untuk membatik dengan ornamen yang unik seperti bunga, daun, pemandangan, kupu-kupu dan ornamen khas anak-anak lainnya sebagai hasil dari kreativitas mereka.
\end{abstract}

Kata kunci: batik, kreativitas, siswa sekolah dasar

\begin{abstract}
Batik is original Indonesian art that must be preserved. One of the ways to do it is to introduce batik to the children. This community service activity is a training of batik process which aims to introduced batik and training batik process as an effort to the preservation and increases the creativity of elementary school students in Padang Panjang city. The method of community service uses lecturer, demonstration, and training. The output of show hight enthusiastic of students to create batik with a unique ornament like flowers, leaf, view of nature, butterfly and other typical children's ornament as the result of the creativity.
\end{abstract}

Keywords: batik, creativity, elementary school students

Copyright (c) 2021 Yulimarni, Ahmad Bahrudin, Widdiyanti, Wisnu Prastawa, Taufik Akbar

$\triangle$ Corresponding author

Address : Institut Seni Indonesia Padang Panjang

Email : taufik723@gmail.com

ISSN 2721- 9224 (Media Cetak)

DOI : https://doi.org/10.31004/abdidas.v2i1.230

ISSN 2721- 9216 (Media Online) 
115 Pelatihan Batik Berbasis Kreativitas pada Siswa Sekolah Dasar Kota Padang Panjang- Yulimarni, Ahmad Bahrudin, Widdiyanti, Wisnu Prastawa, Taufik Akbar

DOI: https://doi.org/10.31004/abdidas.v2i1.230

\section{PENDAHULUAN}

Indonesia merupakan negara dengan keragaman budaya yang tersebar di berbagai daerah. Keragaman budaya tersebut dapat dilihat dari berbagai hasil kesenian tradisional yang mencerminkan kearifan lokal (local wisdom) sebagai identitas masyarakat timur. Beberapa hasil kesenian tradisional terdapat pada hampir semua cabang seni, mulai dari tari-tarian, musik, pakaian adat, arsitektur tradisional hingga benda-benda kriya dan kerajinan. Semua hasil kesenian tradisional ini merupakan aset berharga bangsa yang harus terus dijaga dan dilestarikan.

Salah satu hasil kesenian tradisional Indonesia yang cukup berharga dan mengenalkan budaya Indonesia pada dunia global adalah batik. Batik merupakan hasil kriya wastra atau tekstil dari Indonesia yang sudah mendapat pengakuan internasional sebagai salah satu Budaya Tak Benda Warisan Manusia (Intangible Cultural Heritage of Humanity) dunia melalui UNESCO sejak 2 Oktober 2009 di Abu Dhabi, Uni Emirat Arab. Dengan demikian batik pun resmi menjadi salah satu representasi budaya asli Indonesia (MD, 2009).

Sejak diakui UNESCO, pemerintah Indonesia semakin masif mempopulerkan batik di tengah-tengah masyarakat. Setiap tanggal 2 Oktober pun diperingati sebagai hari batik atau hari berbusana batik nasional. Dengan pengakuan ini pemerintah juga berusaha agar batik dapat dikenal dan digunakan oleh setiap generasi khususnya generasi muda sebagai upaya untuk melestarikannya agar tidak hilang digerus kemajuan zaman. Upaya mempopulerkan batik di tengah-tengah masyarakat secara tidak langsung membuat batik semakin menyebar di seluruh Indonesia. Tidak hanya itu, pemerintah juga mendorong agar setiap daerah memiliki batik khas daerahnya masing-masing.

Salah satu upaya pelestarian batik adalah dengan mengenalkan dan mengajarkan batik pada anak-anak sejak dini, khususnya pada anak usia sekolah dasar. Selain untuk tujuan pelestarian pemilihan anak-anak usia sekolah dasar dalam pengenalan batik ini juga karena faktor tentang melatih kreativitas. Semua cabang seni termasuk batik pada dasarnya sangat berkaitan dengan bagaimana mengasah kreativitas dan hal ini menjadi tepat untuk siswa-siswa SD. Anak-anak pada usia sekolah dasar dapat dikatakan menjalani fase penting dalam perkembangan yang mempengaruhi kualitas sumber daya manusia di masa-masa selanjutnya, karena siswa SD pada umumnya memiliki rasa ingin tahu, tanggap terhadap masalah dan kompleksitasnya serta minat untuk memahami suatu fenomena secara bermakna. Oleh karena itu penekanan kemampuan berpikir kreatif menjadi penting di tingkat sekolah dasar (Dasar, 2016).

Terdapat banyak pendapat tentang kreativitas dari beberapa ahli. Dari beberapa pendapat tersebut pada intinya merujuk pada kemampuan sesorang untuk menemukan gagasan atau menghasilkan sesuatu yang baru. Kreatif juga sering dikaitkan sebagai sebuah solusi dari suatu pemecahan masalah. Kreativitas dianggap sebagai solusi untuk melatih keterampilan memecahkan masalah, memberikan kepuasan serta meningkatkan kualitas hidup (Kau, 2017). Dua ciri 
116 Pelatihan Batik Berbasis Kreativitas pada Siswa Sekolah Dasar Kota Padang Panjang- Yulimarni, Ahmad Bahrudin, Widdiyanti, Wisnu Prastawa, Taufik Akbar

DOI: https://doi.org/10.31004/abdidas.v2i1.230

kreativitas ini tentu perlu diasah sejak kecil pada anak-anak.

Bukti penting tentang kreativitas dalam membuat sehelai kain batik dapat dilihat pada motif-motif/ragam hias batik itu sendiri. Batik berasal dari bahasa jawa yaitu kata $m b a$ dan tik yang artinya adalah menulis titik (seni menulis titik pada kain). Batik juga didefinisikan sebagai seni menggambar/menghias pada kain polos dengan teknik menutup kain menggunakan lilin atau malam pada bagian yang tidak diinginkan untuk diwarna. Secara khusus batik dapat diartikan sebagai seni menulis atau melukis di atas kain yang dibuat dengan teknik merintang warna menggunakan lilin untuk mendapatkan ornamen/ragam hias atau pola tertentu menggunakan canting (Supriono, 2016). Dengan mengajarkan siswa SD membatik inilah diharapkan lahir ornamen hias orisinil dan otentik yang lahir dari ide kreatif siswa-siswa SD tersebut.

Batik selama ini identik berasal dan hanya terdapat di pulau Jawa. Pendapat ini sedikit keliru karena sebenarnya dahulu beberapa daerah lain di luar Jawa sudah memiliki batiknya sendiri-sendiri, namun memang tidak sebanyak di Jawa. Batik pun sebenarnya dapat dipelajari dimana saja dan ragam coraknya dapat disesuaikan dengan daerah masingmasing. Selain itu dengan sudah menasionalnya batik sebagai pakaian khas Indonesia maka beberapa daerah juga didorong untuk mengembangkan batik khasnya masing-masing, baik untuk pariwisata maupun ekonomi.

Kota Padang Panjang yang berdekatan dengan Bukittinggi merupakan salah satu kota di Sumatera Barat yang mulai giat mengembangkan pariwisata sebagai andalan daerahnya, baik itu berbasis alam, pendidikan hingga seni dan budaya. Di kota ini juga terdapat perguruan tinggi seni yaitu Institut Seni Indonesia (ISI) Padangpanjang yang dapat berkolaborasi dengan pemerintah dan masyarakat dalam mengembangkan seni dan pariwisata tersebut. Oleh karena itu kegiatankegiatan pengenalan keterampilan membatik pada siswa-siswa SD di Kota Padang Panjang ini merupakan langkah awal untuk melestarikan batik dan melatih kreativitas anak-anak usia sekolah dasar. Untuk jangka kegiatan ini setidaknya dapat membuka peluang untuk nantinya mulai dikembangkan batik khas Padang Panjang sebagai salah satu komoditi penunjang ekonomi dan pariwisata setempat.

\section{METODE}

Pada pengabdian ini mitra merupakan siswa-siswa dari beberapa sekolah dasar yang terdapat di Kota Padang Panjang. Kegiatan dilakukan di Lapangan Banca Laweh, Kota Padang Panjang pada tanggal 21-22 Maret 2020. Kriteria mitra merupakan anak usia sekolah dasar mulai dari kelas I hingga kelas VI. Target dari kegiatan ini adalah mitra dapat mengenal batik, mengetahui proses batik dan dapat belajar membatik.

Metode yang digunakan dalam kegiatan pengabdian ini adalah melalui ceramah, demostrasi dan pelatihan. Metode ceramah melalui pengenalan tentang batik pada mitra (siswa-siswa SD). Demonstrasi dilakukan dengan melakukan peragaan bagaimana proses membatik mulai dari membuat sketsa ornamen pada kain, mencanting hingga proses pewarnaan kain batik. Siswa-siswa 
117 Pelatihan Batik Berbasis Kreativitas pada Siswa Sekolah Dasar Kota Padang Panjang- Yulimarni, Ahmad Bahrudin, Widdiyanti, Wisnu Prastawa, Taufik Akbar

DOI: https://doi.org/10.31004/abdidas.v2i1.230

SD pun diberi kebebasan untuk membuat corak motif batik sesuai dengan kreativitasnya. Sasarannya agar mitra dapat lebih dahulu menganggap membatik merupakan sesuatu hal yang menyenangkan. Berikut ini adalah tahaptahap kegiatan yang dilakukan:

1. Perencanaan berupa persiapan media kegiatan pelatihan

2. Pelaksanaan meliputi kegiatan berikut:

a) Pengenalan batik secara umum kepada mitra.

b) Demonstrasi proses pembatik oleh instruktur.

c) Para siswa menggambar motif batik dengan pensil di atas kain berukuran $35 \times 45 \mathrm{~cm}$.

d) Siswa SD mencanting motif yang sudah dibuat.

e) Siswa SD mewarnai kain batik dan finishing hingga menjadi karya batik.

3. Evaluasi karya pelatihan.

Pada pengabdian ini peserta dikenalkan dan diajarkan dengan batik tulis. Batik tulis menitik beratkan pada keterampilan tangan dan merupakan keahlian mendasar dalam keahlian membatik. Selain itu, dengan metode batik tulis mitra dapat lebih bebas berkreativitas karena siswa langsung membatik dengan canting menggunakan tangan. Dengan demikian, siswa dapat lebih leluasa membuat berbagai corak batik yang menarik. Batik tulis juga memiliki nilai estetis yang dekat dengan rasa manusia karena pembuatan motif langsung dikerjakan dengan tangan. Teknik ini menjadikan batik tulis memiliki ciri khas yang menuntut tingkat ketelitian dan kesabaran manusia (Yudhoyono, 2010).

\section{HASIL DAN PEMBAHASAN}

Pelatihan membatik bagi siswa SD di Kota Padang Panjang merupakan sebuah kegiatan pembelajaran yang diberikan kepada anak usia sekolah dasar dalam rangka mengenalkan dan memberikan keterampilan membatik serta sebagai salah satu ajang dalam meningkatkan kreativitas. Siswa-siswa SD selain ditanamkan kemampuan tentang aspek pengetahuan (kognitif) dan sikap (afektif) juga butuh ditanamkan daya kemampuan aspek keterampilan (psikomotorik) untuk mencapai masyarakat yang berpendidikan (Sciences et al., 2020). Kegiatan pelatihan batik edukasi ini mendapatkan tanggapan positif dari mitra. Tidak hanya para siswa, para guru dan orang tua yang mendampingi anaknya juga tertarik dan antusias dengan proses kegiatan membatik.

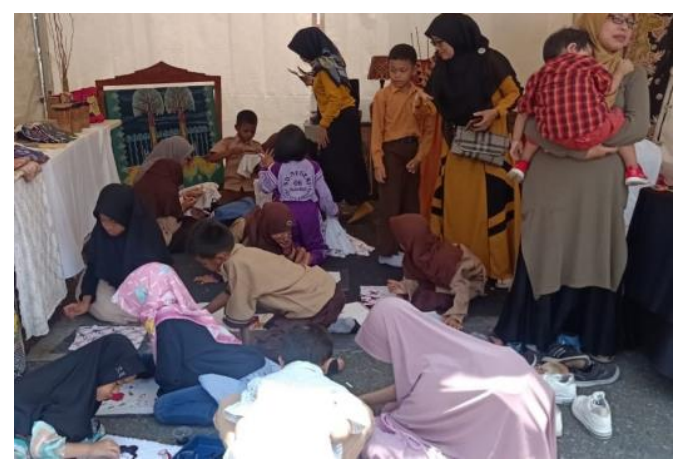

Gambar 1. Antusias Mitra pada Kegiatan Pengabdian.

Kegiatan membatik pada siswa Kota Padang Panjang yang berlangsung selama dua hari dilakukan dengan fleksibel. Para mitra yang notabene masih anak-anak tidak dipaksa untuk 
118 Pelatihan Batik Berbasis Kreativitas pada Siswa Sekolah Dasar Kota Padang Panjang- Yulimarni, Ahmad Bahrudin, Widdiyanti, Wisnu Prastawa, Taufik Akbar

DOI: https://doi.org/10.31004/abdidas.v2i1.230

dapat menyelesaikan sebuah karya batik dalam satu hari. Hal ini karena karakter siswa SD terutama kelas I dan II yang masih senang bermain, meskipun demikian mereka tetap diberikan bimbingan dalam setiap proses tahapan dalam membatik. Capaian dari kegiatan ini menekankan pada mitra dapat mengetahui proses membatik dan dengan membatik juga dapat menyalurkan kreativitas layaknya kegiatan seni lainnya seperti menggambar atau mewarnai.

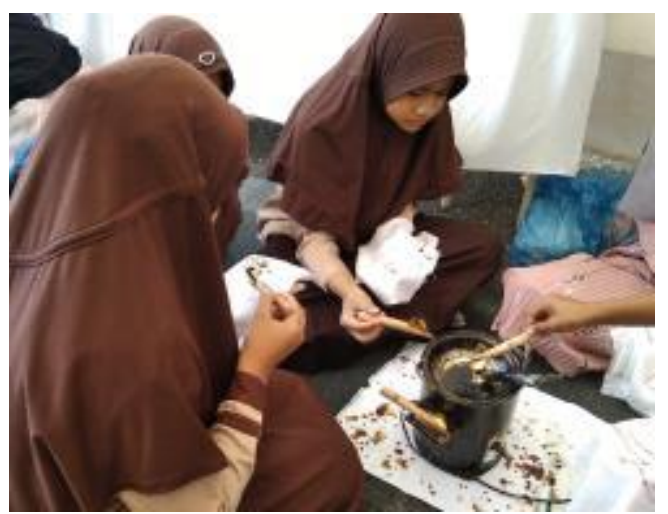

Gambar 2. Aktivitas Siswa SD Mencanting

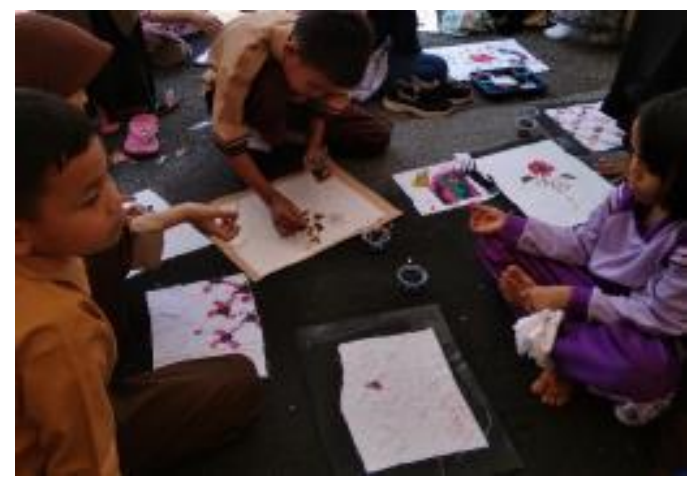

Gambar 3. Aktivitas Siswa SD Mewarnai Batik

Dari beberapa hasil karya batik siswa dapat disampaikan bahwa mitra sudah belajar mengasah dan menggunakan kreativitasnya untuk mewujudkan corak batik dengan ornamenornamen yang menarik. Para siswa umumnya membuat corak batik yang dekat dengan kehidupannya dan sesuai usianya. Corak ornamen yang dibuat diantaranya motif bunga, daun, pemandangan, kupu-kupu dan rumah-rumah.

Pada dasarnya ornamen apapun dapat dibuat menjadi batik. Tidak ada keharusan atau pakem bahwa batik harus memiliki motif-motif tertentu. Motif adalah ornamen secara keseluruhan dan ornamen sendiri merupakan objek gambar atau citra yang berfungsi sebagai elemen hias seperti (Kusrianto, 2013). Oleh karena itu pada intinya setiap goresan yang dibuat untuk mengisi dan menghias kain batik menjadi ornamen batik.

Evaluasi yang dilakukan setelah karya batik siswa selesai menunjukkan bahwa pelaksanaan kegiatan sesuai dengan target yang diinginkan terhadap mitra. Para siswa mampu berkreasi menciptakan motif-motif batik yang mencerminkan kemampuannya menuangkan ide dan gagasannya untuk mewujudkan sebuah karya batik di atas kain. Walaupun secara kualitas batik yang dihasilkan belum maksimal namun antusias dan semangat para siswa dalam kegiatan sudah menunjukkan ketertarikan pada proses membatik.

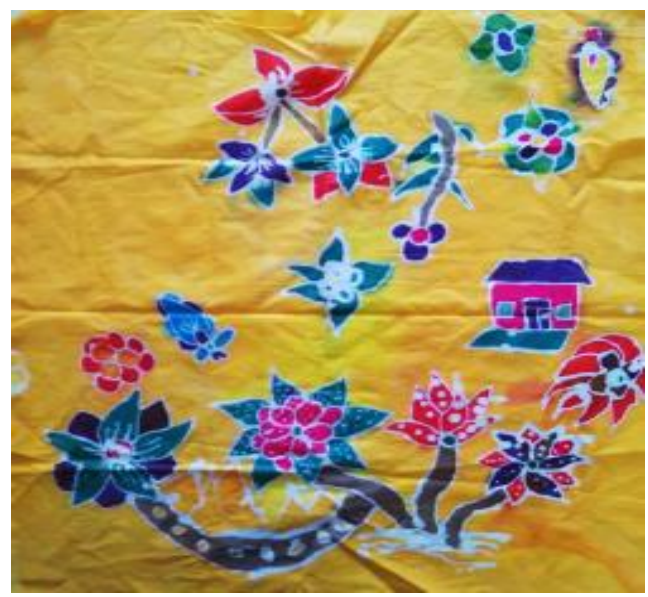

Gambar 4. Hasil Karya Batik Siswa SD 
119 Pelatihan Batik Berbasis Kreativitas pada Siswa Sekolah Dasar Kota Padang Panjang- Yulimarni, Ahmad Bahrudin, Widdiyanti, Wisnu Prastawa, Taufik Akbar

DOI: https://doi.org/10.31004/abdidas.v2i1.230

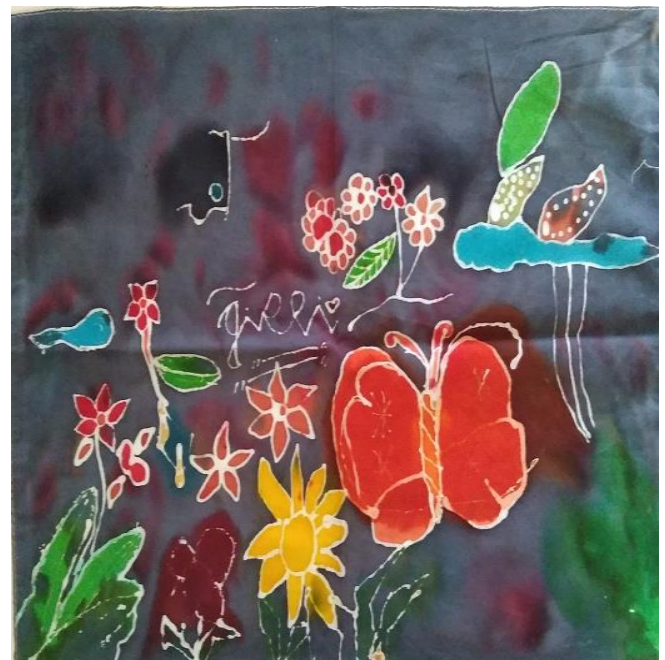

Gambar 5. Hasil Karya Batik Siswa SD

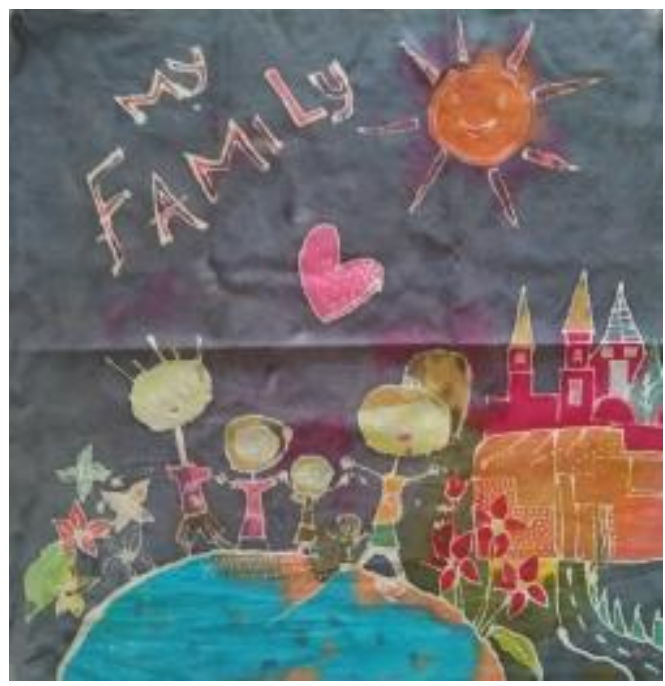

Gambar 6. Hasil Karya Batik Siswa SD

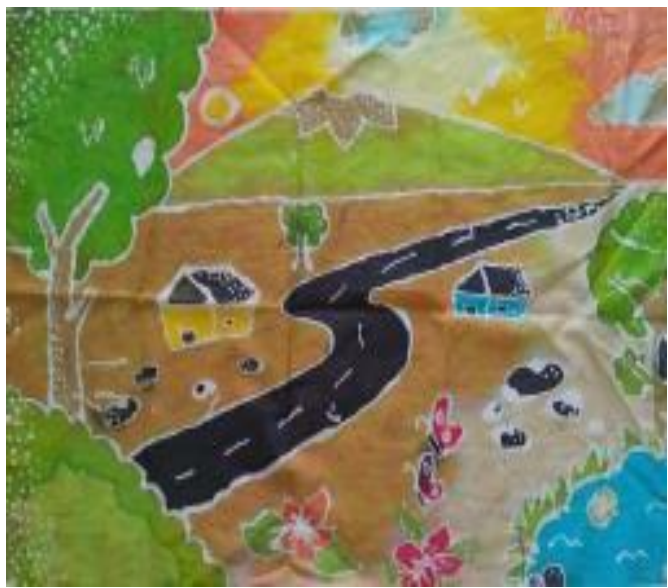

Gambar 7. Hasil Karya Batik Siswa SD

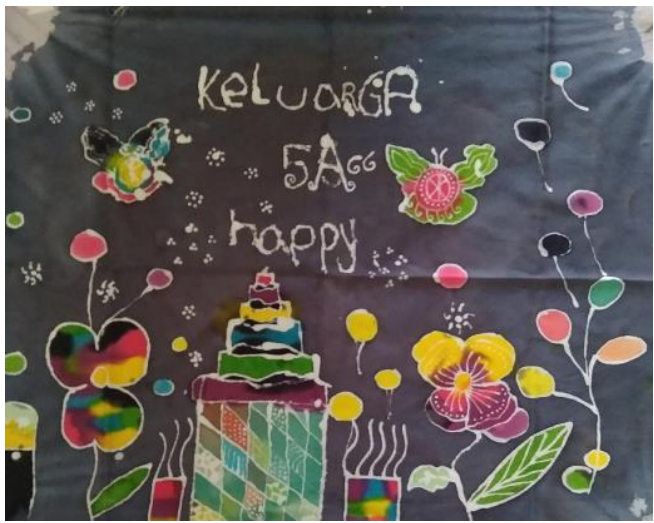

Gambar 8. Hasil Karya Batik Siswa SD

\section{SIMPULAN}

Kegiatan pelatihan membatik berbasis kreativitas yang dilaksanakan pada anak usia sekolah dasar di Kota Padang Panjang secara umum terlaksana sesuai dengan rencana. Peserta mendapatkan pembelajaran membatik khususnya batik tulis dan telah merasakan bagaimana cara membuat desain batik, mencanting dan mewarnai, hingga menjadi sebuah karya batik dengan kreativitas masing-masing. Melalui program tersebut, peserta memperoleh pengetahuan dan lebih mengenal batik sebagai warisan budaya bangsa Indonesia yang harus dilestarikan. Para siswa SD dapat berkreasi, membuat dan menciptakan batik tulis sehingga peserta menjadi paham tentang apa itu batik yang sesungguhnya.

Diharapkan kegiatan pelatihan membatik ini dapat terus berlanjut tidak hanya untuk anak-anak, namun juga kepada masyarakat yang lebih luas sebagai usaha pelestarian budaya bangsa dan tidak menutup kemungkinan sebagai langkah awal untuk menghasilkan perajin-perajin batik baru yang dapat meningkatkan ekonomi masyarakat dan daerah. 
120 Pelatihan Batik Berbasis Kreativitas pada Siswa Sekolah Dasar Kota Padang Panjang- Yulimarni, Ahmad Bahrudin, Widdiyanti, Wisnu Prastawa, Taufik Akbar

DOI: https://doi.org/10.31004/abdidas.v2i1.230

\section{UCAPAN TERIMA KASIH}

Dengan telah terlaksananya kegiatan pelatihan batik berbasis kreativitas pada siswa sekolah dasar di Padang Panjang ini, ucapan terima kasih sebanyak-banyaknya tidak lupa disampaikan kepada LPPMPP ISI Padangpanjang, Dinas Pendidikan Kota Padang Panjang, Dinas Perpustakaan Daerah Kota Padang Panjang, serta para siswa, guru, masyarakat sekitar dan semua pihak yang telah ikut berpartisipasi mendukung kegiatan pengabdian ini.

\section{DAFTAR PUSTAKA}

Dasar, S. S. (2016). Mengembangkan Kreativitas Siswa Sekolah Dasar. Metodik Didaktik: Jurnal Pendidikan Ke-SD-An, 9(2), 25-33. https://doi.org/10.17509/md.v9i2.3250

Kau, M. A. (2017). Peran Guru Dalam Mengembangkan Kreativitas Anak Sekolah Dasar. Proceeding Seminar Dan Lokakarya Nasional Bimbingan Dan Konseling 2017, $O(0), \quad$ 157-166. http://journal2.um.ac.id/index.php/sembk/arti cle/view/1281

Kusrianto, A. (2013). Batik; Filosofi, Motif \& Kegunaan (R. B. W (ed.)).

MD, I. U. (2009). Batik dan Kontribusinya. Jurnal Bestari Universitas Muhamadiyah Malang, 42(1), 21-32. http://ejournal.umm.ac.id/index.php/bestari/a rticle/viewFile/91/103_umm_scientific_journ al.doc

Sciences, H., Pebriana, P. H., Pahlawan, U., Tambusai, T., \& Pengajaran, M. (2020). Jurnal abdidas. 1(1).

Supriono, P. (2016). Ensiklopedia The Heritage of Batik; Identitas Pemersatu Kebanggan Bangsa (Maya (ed.)). Penerbit ANDI.

Yudhoyono, B. A. (2010). Batikku; Pengabdian Cinta tak Berkata. Gramedia Pustaka Utama. 